Article

\title{
Neuraminidase Inhibitory Activity and Constituent Characterization of Fagopyrum dibotrys
}

\author{
Xiang Zhang ${ }^{1}$ (D), Yu Cao ${ }^{1}$, Jinhua $\mathrm{Li}^{1}{ }^{1}$, Ailin Liu ${ }^{2}$, Haibo Liu ${ }^{1, *}$ and Linfang Huang ${ }^{1, *}$ \\ 1 Institute of Medicinal Plant Development, Peking Union Medical College \& Chinese Academy of Medical \\ Sciences, Beijing 100193, China; 18364166427@163.com (X.Z.); caoyu0709@139.com (Y.C.); \\ jinhuali108@126.com (J.L.) \\ 2 Institute of Materia Medica, Chinese Academy of Medical Sciences \& Peking Union Medical College, \\ Beijing 100050, China; liuailin@imm.ac.cn \\ * Correspondence: hbliu@implad.ac.cn (H.L.); lfhuang@implad.ac.cn (L.H.); \\ Tel.: +86-10-57833197 (L.H.); Fax: +86-10-62899700 (L.H.)
}

Received: 21 October 2017; Accepted: 15 November 2017; Published: 18 November 2017

\begin{abstract}
This study aimed to identify a new biological activity of the widely distributed species Fagopyrum dibotrys. Four F. dibotrys extracts (ethyl acetate (EA), petroleum ether (P), ethanol (E), and water (W)) were explored for their anti-neuraminidase (NA) activity. A total of 32 compounds were identified using UHPLC-Q-Exactive Orbitrap HRMS in the EA extract, which had the best NA inhibitory effects. We used the docking data for supporting compounds' anti-neuraminidase activity. Among them, five compounds including one flavonoid, three organic acids, and one glucoside were discovered for the first time in F. dibotrys. Docking studies and NA activity assay revealed the remarkable NA inhibitory activity of eight components in EA extract, especially rutin, hesperidin, procyanidin $\mathrm{B}_{2}$, and quercitrin. Therefore, $F$. dibotrys could be used to develop anti-influenza drugs.
\end{abstract}

Keywords: Fagopyrum dibotrys; NA inhibitory activity; UHPLC-Q-Exactive; molecular docking; chemical constituents

\section{Introduction}

Fagopyrum dibotrys is an important crude drug and functional food that has been widely used in traditional Chinese medicine (TCM) [1]. It mainly grows in China, Vietnam, India, and Thailand [2]. The herb, which has been recorded in the Chinese Pharmacopoeia since 1977, is a functional food and has been approved by National Health and Family Planning Commission of the People's Republic of China (NHFPC). It also called Fagopyrum cumosum (Trev.) Meisn, whose rhizome was considered as folk medicine for clearing away heat and toxic materials, expelling pus and removing blood stasis [3-5]. Until recently, some biological activities of $F$. dibotrys, including anti-oxidant, anti-tumor, anti-inflammatory, anti-bacterial [6-8], and so on have been reported, but anti-influenza activity is unknown.

The Q-Exactive system with the its high resolving power performance easily combines with ultra-high performance liquid chromatography (UHPLC). UHPLC-Q-Exactive Orbitrap high resolution mass spectrometry (HRMS) can rapidly detect hundreds of components in complex compound mixtures from plants with short running times [9]. Similarly, molecular docking is a reliable and efficient tool for discovering or designing novel drugs used to screen biological chemical compounds [10-13]. In the present work (see Figure 1 for a flowchart of the protocol used), four F. dibotrys extracts (ethyl acetate (EA), petroleum ether $(\mathrm{P})$, ethanol $(\mathrm{E})$, and water $(\mathrm{W})$ ) were explored in a neuraminidase (NA) activity assay, with the components of the best extract being further identified by UHPLC-Q-Exactive Orbitrap HRMS. To further validate the NA inhibitory activity of $F$. dibotrys, eight components were docked to the NA inhibition target using molecular docking technology and tested in NA inhibition 
experiments. Based on the theory that NA is an important target to screen the anti-influenza virus drugs due to the fact it has the essential enzyme activity for virus replication and NA inhibitors are recognized as an effective drugs against influenza A and B by the World Health Organization [14], this research will provide a new direction and basic information for novel anti-influenza virus drug discovery.

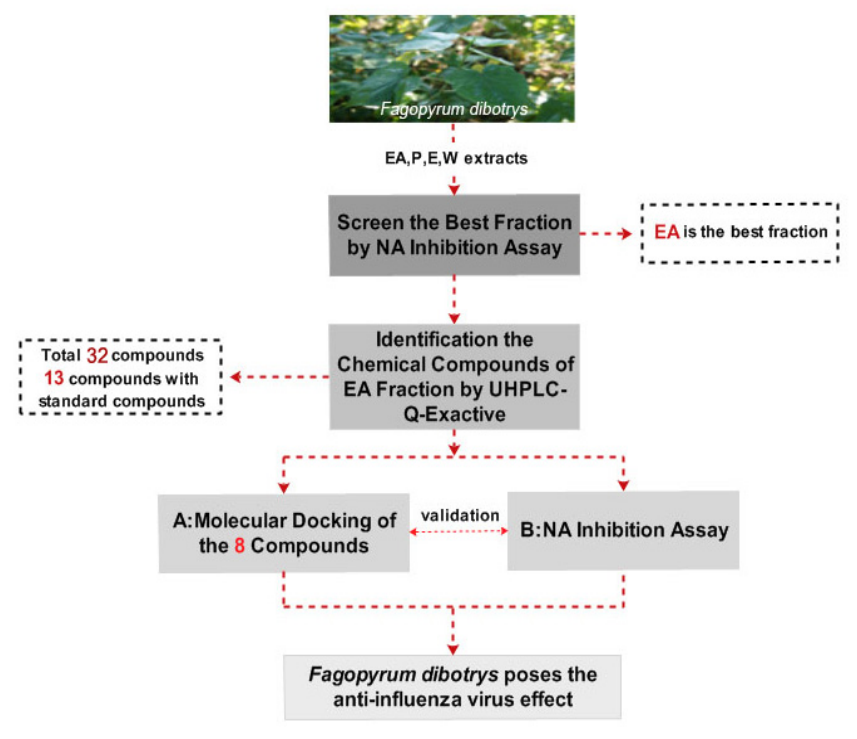

Figure 1. The flowchart of the paper.

\section{Result and Discussion}

\subsection{Influenza Virus Neuraminidase (NA) Activity Assay of Four Extracts}

NA has been considered as an important target to screen anti-influenza virus drugs. NA inhibitory activities of the four extracts are shown in Figure 2. They all indicated dose-dependent activity. The lower $\mathrm{IC}_{50}$ value implies a higher activity. Based on the $\mathrm{IC}_{50}$ values, two extracts are good and $\mathrm{EA}$ is the best one. The $\mathrm{IC}_{50}$ of EA and $\mathrm{P}$ are 149 and $182 \mu \mathrm{g} / \mathrm{mL}$, respectively. The activity order is EA $>\mathrm{P}$ $>\mathrm{E}>\mathrm{W}$.

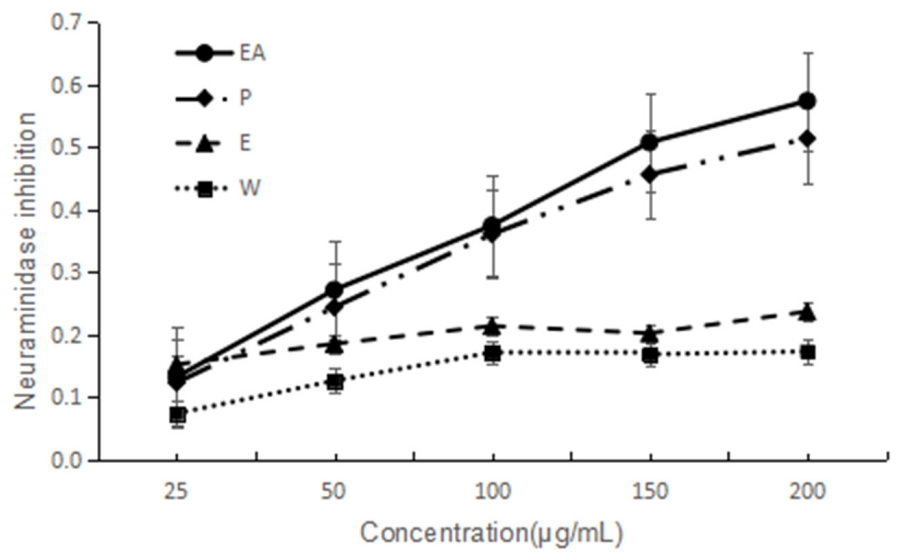

Figure 2. NA inhibitory activity of four extracts of F. dibotrys. EA: ethyl acetate fraction; P: petroleum ether fraction; $\mathrm{E}$ : ethanol fraction; $\mathrm{W}$ : water fraction.

\subsection{Identification of Chemical Compositions of EA Extract by UHPLC-Q-Exactive}

The identification of the chemical components of the F. dibotrys EA extract was investigated using UHPLC-Q-Exactive HRMS. Based on the retention time, standard substances, molecular ions, and 
major fragments were observed in MS spectra, followed by a search of an online database (METLIN) and literature reports, wherein 32 chemical structures were tentatively identified and were definitely classified into four groups: flavonoids, tannins, organic acids, and others. Figures 3 and 4 show the EA extract base peak chromatogram (BPC) and the chemical structures of the main identified compounds, respectively. The identified compounds, retention time, molecular formula, exact mass, experimental mass, the major fragments, and references are listed in Table 1.

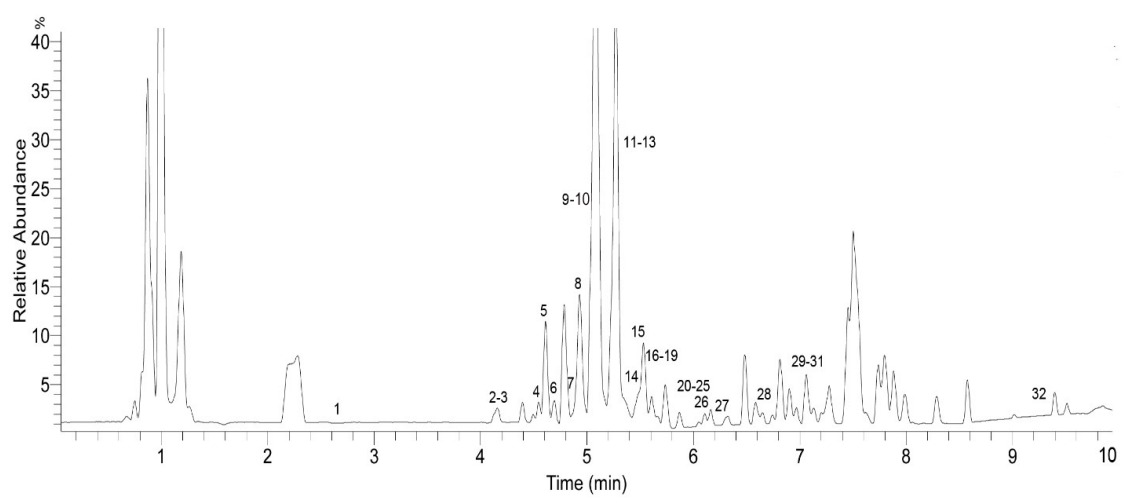

Figure 3. Base peak chromatogram (BPC) of the ethyl acetate fraction (EA) of F. dibotrys (negative ion mode).<smiles>O=c1c(O)cc(O)cc2oc(-c3cc(Br)c(O)c(Br)c3)c(Br)c12</smiles>

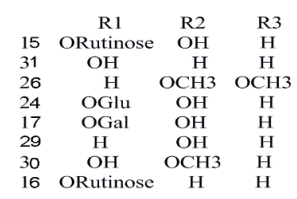<smiles>[R9]c1ccc(C2CC(=O)c3c([125I])cc([2H])cc3O2)cc1[18OH]</smiles>

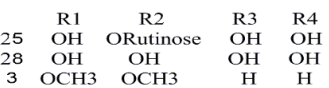<smiles>[Y]C(=O)c1cc([R3])c(O)c([R])c1</smiles><smiles>[R10]C(=O)O[Ga]</smiles>
$\begin{array}{llll}11 & \mathrm{OH} & \mathrm{OH} & \mathrm{OCH} 3 \\ 21 & \mathrm{OH} & \mathrm{OH} & \mathrm{OCH} 2 \mathrm{CH}\end{array}$<smiles>Cc1cc(O)c2c(c1)C(=O)c1cc(O)cc(O)c1C2=O</smiles>
Emodin<smiles>Cc1cc(N)c2c(c1)OC(c1cc(N)c(N)c(O)c1)[C@H](C)C2</smiles>

$\begin{array}{lllllll} & \text { R1 } & \text { R2 } & \text { R3 } & \text { R4 } & \text { R5 } & \text { R6 } \\ 13 & \text { OH } & \text { OH } & \text { OH } & \text { OH } & \text { OH } & \text { H }\end{array}$ $12 \mathrm{OH}$ OH $\mathrm{OH}$ OH $\mathrm{OH}$<smiles>[2H]c1cc(C(=O)O)cc(Br)c1Br</smiles>
$\begin{array}{cccc} & \text { R1 } & \text { R2 } & \text { R3 } \\ 18 & \text { H } & \text { H } & \text { H } \\ 22 & \text { OCH3 } & \text { OH } & \text { OCH3 } \\ 4 & \text { OCH3 } & \text { OH } & \text { H } \\ 2 & \text { OH } & \text { OH } & \text { OH } \\ 6 & \text { OH } & \text { OH } & \text { H } \\ 23 & \text { OH } & \text { OCH3 } & \text { H } \\ 10 & \text { H } & \text { OH } & \text { H }\end{array}$<smiles>[R]c1cc(/C=C/C(=O)O)ccc1O</smiles><smiles>Nc1cc(O)c2c(c1[C@H]1c3cc(O)cc(O)c3O[C@H](c3ccc(O)c(O)c3)[C@@H]1O)O[C@H](c1ccc(O)c(O)c1)[C@H](O)C2</smiles>

procyanidin B2

Figure 4. Chemical structures of the main identified compounds in the EA extract from F. dibotrys. 
Table 1. Thirty-two chemical constituents identified in the ethyl acetate fraction (EA) of F. dibotrys extracts using UHPLC-Q-Exactive.

\begin{tabular}{|c|c|c|c|c|c|c|c|}
\hline Peak & Assigned Identify & Rt (min) & Formula Ions & Calculated $(\mathrm{m} / \mathrm{z})$ & Experimental $(\mathrm{m} / \mathrm{z})$ & Fragment Ions & Reference Sources \\
\hline 1 & succinic acid & 2.65 & $\mathrm{C}_{4} \mathrm{H}_{6} \mathrm{O}_{4}$ & 117.01824 & 117.01784 & 73 & [3] \\
\hline 2 & gallic acid & 4.13 & $\mathrm{C}_{7} \mathrm{H}_{6} \mathrm{O}_{5}$ & 169.01315 & 169.01306 & 125 & [15] \\
\hline 3 & 5,7-dimethoxyflavanone & 4.16 & $\mathrm{C}_{17} \mathrm{H}_{15} \mathrm{O}_{4}$ & 282.08866 & 282.08411 & 268 & First report in F. dibotrys \\
\hline 4 & Vanillic acid & 4.56 & $\mathrm{C}_{8} \mathrm{H}_{8} \mathrm{O}_{4}$ & 167.03389 & 167.03386 & 149 & First report in F. dibotrys \\
\hline 5 & glucosyringic acid & 4.61 & $\mathrm{C}_{15} \mathrm{H}_{20} \mathrm{O}_{10}$ & 359.09727 & 359.09808 & 197 & First report in F. dibotrys \\
\hline 6 & protocatechuic acid & 4.69 & $\mathrm{C}_{7} \mathrm{H}_{6} \mathrm{O}_{4}$ & 153.01824 & 153.0181 & 109 & {$[3]$} \\
\hline 7 & ferulic acid & 4.84 & $\mathrm{C}_{10} \mathrm{H}_{10} \mathrm{O}_{4}$ & 193.04954 & 193.04948 & 178 & [13] \\
\hline 8 & chlorogenic acid & 4.93 & $\mathrm{C}_{16} \mathrm{H}_{18} \mathrm{O}_{9}$ & 353.08671 & 353.08743 & 191 & [3] \\
\hline 9 & procyanidin $B_{2}$ & 5.08 & $\mathrm{C}_{30} \mathrm{H}_{26} \mathrm{O}_{12}$ & 577.13405 & 577.13464 & 289 & [3] \\
\hline 10 & 4-hydroxybenzoic acid & 5.15 & $\mathrm{C}_{7} \mathrm{H}_{6} \mathrm{O}_{3}$ & 137.02332 & 137.02303 & 93 & {$[3]$} \\
\hline 11 & 4-o-methyl-gallate & 5.20 & $\mathrm{C}_{8} \mathrm{H}_{8} \mathrm{O}_{5}$ & 183.0288 & 183.02884 & 169,125 & [12] \\
\hline 12 & (-)epicatechin & 5.27 & $\mathrm{C}_{15} \mathrm{H}_{14} \mathrm{O}_{6}$ & 289.07066 & 289.07141 & 245 & [3] \\
\hline 13 & $(+)$-catechin & 5.27 & $\mathrm{C}_{15} \mathrm{H}_{14} \mathrm{O}_{6}$ & 289.07066 & 289.07141 & 245 & [2] \\
\hline 14 & caffeic acid & 5.32 & $\mathrm{C}_{9} \mathrm{H}_{8} \mathrm{O}_{4}$ & 179.03389 & 179.03378 & 135 & {$[13]$} \\
\hline 15 & rutin & 5.53 & $\mathrm{C}_{27} \mathrm{H}_{30} \mathrm{O}_{16}$ & 609.14501 & 609.14612 & 301 & {$[2,3]$} \\
\hline 16 & kaempferol-3-o-rutinoside & 5.55 & $\mathrm{C}_{27} \mathrm{H}_{30} \mathrm{O}_{15}$ & 593.1501 & 593.15076 & & [3] \\
\hline 17 & hyperoside & 5.69 & $\mathrm{C}_{21} \mathrm{H}_{20} \mathrm{O}_{12}$ & 463.0871 & 463.08832 & 301,271 & [5] \\
\hline 18 & benzoic acid & 5.71 & $\mathrm{C}_{7} \mathrm{H}_{6} \mathrm{O}_{2}$ & 121.02841 & 121.02805 & 77 & [3] \\
\hline 19 & ellagic acid & 5.72 & $\mathrm{C}_{14} \mathrm{H}_{6} \mathrm{O}_{8}$ & 300.99789 & 300.99881 & 299.01556 & First report in F. dibotrys \\
\hline 20 & 4-Hydroxycinnamic acid & 5.82 & $\mathrm{C}_{9} \mathrm{H}_{8} \mathrm{O}_{3}$ & 163.03897 & 163.03893 & 146,119 & - \\
\hline 21 & ethyl gallate & 5.83 & $\mathrm{C}_{9} \mathrm{H}_{10} \mathrm{O}_{5}$ & 197.04445 & 197.0446 & 169,153 & [14] \\
\hline 22 & Syringic acid & 5.84 & $\mathrm{C}_{9} \mathrm{H}_{10} \mathrm{O}_{5}$ & 197.04445 & 197.04466 & 153 & [13] \\
\hline 23 & 3-hydroxy-4-methoxybenzoic acid & 5.93 & $\mathrm{C}_{8} \mathrm{H}_{8} \mathrm{O}_{4}$ & 167.03389 & 167.03386 & & First report in F. dibotrys \\
\hline 24 & quercitrin & 5.95 & $\mathrm{C}_{21} \mathrm{H}_{20} \mathrm{O}_{11}$ & 447.09219 & 447.09296 & 301 & {$[2,3]$} \\
\hline 25 & hesperidin & 6.00 & $\mathrm{C}_{28} \mathrm{H}_{34} \mathrm{O}_{15}$ & 609.1814 & 609.18292 & 301 & [3] \\
\hline 26 & $3^{\prime \prime}, 5^{\prime}$-dimethoxy-4',5,7-trihydroxyflavone & 6.06 & $\mathrm{C}_{17} \mathrm{H}_{14} \mathrm{O}_{7}$ & 329.06558 & 329.06671 & & - \\
\hline 27 & protocatechuic acid methyl ester & 6.23 & $\mathrm{C}_{8} \mathrm{H}_{8} \mathrm{O}_{4}$ & 167.03389 & 167.03389 & 149 & [3] \\
\hline 28 & eriodictyol & 6.79 & $\mathrm{C}_{15} \mathrm{H}_{12} \mathrm{O}_{6}$ & 287.05501 & 287.05585 & & - \\
\hline 29 & luteolin & 6.92 & $\mathrm{C}_{15} \mathrm{H}_{10} \mathrm{O}_{6}$ & 285.03936 & 285.04044 & 133 & [3] \\
\hline 30 & isorhamnetin & 7.02 & $\mathrm{C}_{16} \mathrm{H}_{12} \mathrm{O}_{7}$ & 315.04993 & 315.05099 & 300 & - \\
\hline 31 & kaempferol & 7.13 & $\mathrm{C}_{15} \mathrm{H}_{10} \mathrm{O}_{6}$ & 285.03936 & 285.04059 & 255 & [3] \\
\hline 32 & emodin & 9.22 & $\mathrm{C}_{15} \mathrm{H}_{10} \mathrm{O}_{5}$ & 269.04445 & 269.04535 & 241 & [2] \\
\hline
\end{tabular}




\subsubsection{Flavonoids}

Thirteen flavonoid components were identified [15-17], and among them six peaks $(12,13,15$, 24, 25 and 28) were matched with standard compounds. Peaks 12 and 13, a pair of isomers with a $m / z 289$ molecular ion and a fragment ion of $m / z 245\left[\mathrm{M}-\mathrm{H}-\mathrm{CO}_{2}\right]^{-}$, was proposed to be (-)epicatechin and (+)-catechin, respectively. Peaks 29 and 31, both with a $m / z 285$ molecular ion $[\mathrm{M}-\mathrm{H}]^{-}$, were identified as luteolin and kaempferol, respectively, from a comparison with an online database (METLIN) and literature data. Peak 3 was tentatively identified as 5,7-dimethoxyflavanone for the first time.

\subsubsection{Tannins}

The only tannin in this study, peak 9 , with fragment ions of $m / z 577$ and 289 was proposed to be procyanidin $B_{2}$ which was conformed using a standard.

\subsubsection{Organic Acids}

Twelve organic acid compounds were detected in the EA extract $[3,18,19]$. Among them, three peaks $(2,6,14)$ were identified by comparison with standard compounds. Peak 10, with a molecular ion $[\mathrm{M}-\mathrm{H}]^{-}$at $m / z 137$, and a fragment at $m / z 93$ identified as $\left[\mathrm{M}-\mathrm{H}-\mathrm{CO}_{2}\right]^{-}$was proposed to be 4 -hydroxybenzoic acid. Peaks 4,8 , and 23 were identified as vanillic acid, chlorogenic acid, and 3-hydroxy-4-methoxybenzoic acid, respectively. Peak 8 has a molecular ion at $m / z$ 353, and the fragment ion of $m / z 191\left(\mathrm{M}_{2}\right)$ can be obtained when the ester bond is broken. The ions at $173 \mathrm{~m} / z$ and 154 were proposed to be $\left[\mathrm{M}_{2}-\mathrm{H}-\mathrm{H}_{2} \mathrm{O}\right]^{-}$and $\left[\mathrm{M}_{2}-\mathrm{H}-2 \mathrm{H}_{2} \mathrm{O}\right]^{-}$; these fragments were in accordance with literature reports. Peaks 1 and 7 were identified as succincic acid and ferulic acid. Peaks 14 and 18 were identified as caffeic acid and benzoic acid, respectively, with corresponding fragment ions at $m / z 135\left[\mathrm{M}-\mathrm{H}-\mathrm{CO}_{2}\right]^{-}$and $m / z 77\left[\mathrm{M}-\mathrm{H}-\mathrm{CO}_{2}\right]^{-}$, from a comparison with an online database (METLIN) and literature data.

\subsubsection{Other Compounds}

Peak 11 was proposed to be 4-o-methyl-gallate, whose fragment ions were $m / z 169$ [M - H $\left.\mathrm{CH}_{3}-\mathrm{CO}_{2}\right]^{-}, m / z 125\left[\mathrm{M}-\mathrm{CH}_{3}-\mathrm{CO}_{2}\right]^{-}$[20]. Peak 21 had a molecular ion at $m / z$ 197, and its fragment ions at $m / z 169$ and 125 were identified as [ethyl gallate $\left.-\mathrm{CH}_{3} \mathrm{CH}_{2}\right]^{-}$, and [ethyl gallate $\left.\mathrm{CH}_{3} \mathrm{CH}_{2}-\mathrm{CO}_{2}\right]^{-}$, respectively. The three peaks $11,19,21$ were confirmed using standard compounds and are consistent with previous reports [21].

Peak 5 was identified as glucosyringic acid, with a $m / z 359$ molecular ion; the fragment ion was $[\mathrm{M}-\mathrm{H}-\mathrm{Glu}]^{-}$. The compound protocatechuic acid methyl ester at $6.23 \mathrm{~min}$, showed $\mathrm{m} / \mathrm{z} 167$ and $149\left[\mathrm{M}-\mathrm{H}-\mathrm{H}_{2} \mathrm{O}\right]^{-}$ions. Peak 32, the last compound, was proposed to be emodin with a fragment ion at $m / z 225\left[\mathrm{M}-\mathrm{H}-\mathrm{CO}_{2}\right]^{-}$.

This, a total of 32 compounds, including 13 flavonoids, one tannin, 12 organic acids, and others such as 4-o-methyl-gallate, glucosyringic acid, ethyl gallate, ellagic acid, protocatechuic acid methyl ester, and so on, were tentatively identified. Five compounds, including 5,7-dimethoxyflavanone, vanillic acid, 3-hydroxy-4-methoxybenzoic acid, ellagic acid, and glucosyringic acid, were found for the first time in F. dibotrys. Some of the same compounds, such as quercitrin, kaempferol, -epicatechin, protocatechuic acid, and chlorogenic acid, were previously reported in the genus Fagopyrum (Fagopyrums tataricum and Fagopyrums esculentum) [3].

\subsection{In Silico Docking of Eight Chemical Compounds}

One objective of this study was to compare its results and those of pharmacological neuraminidase assay experiments to confirm the activities of compounds in F. dibotrys. Eight main chemical compounds, such as procyanidin $B_{2}$, rutin, hesperidin, quercitrin, eriodictyol, caffeic acid, (-)epicatechin, and (+)-catechin, were selected for this part of the study. They were docked to 3 TI3 that 
was selected based on the PharmaDB target database. Based on free energy, a higher absolute value implies a higher biological activity. Four compounds had good NA inhibitory activity, and procyanidin $\mathrm{B}_{2}$ was the best one. The indicated docking results were procyanidin $\mathrm{B}_{2}>$ rutin $>$ hesperidin $>$ quercitrin $>$ eriodictyol $>$ caffeic acid $>(-$ )epicatechin $>$ catechin. Figure 5 shows the first four compounds' binding mode with NA. The absolute values of INT can be seen from the Table S1 in supplementary.

A

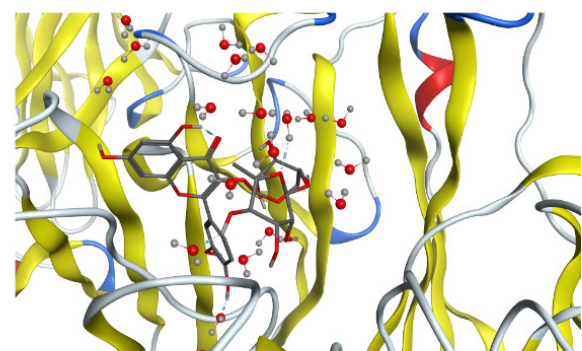

B
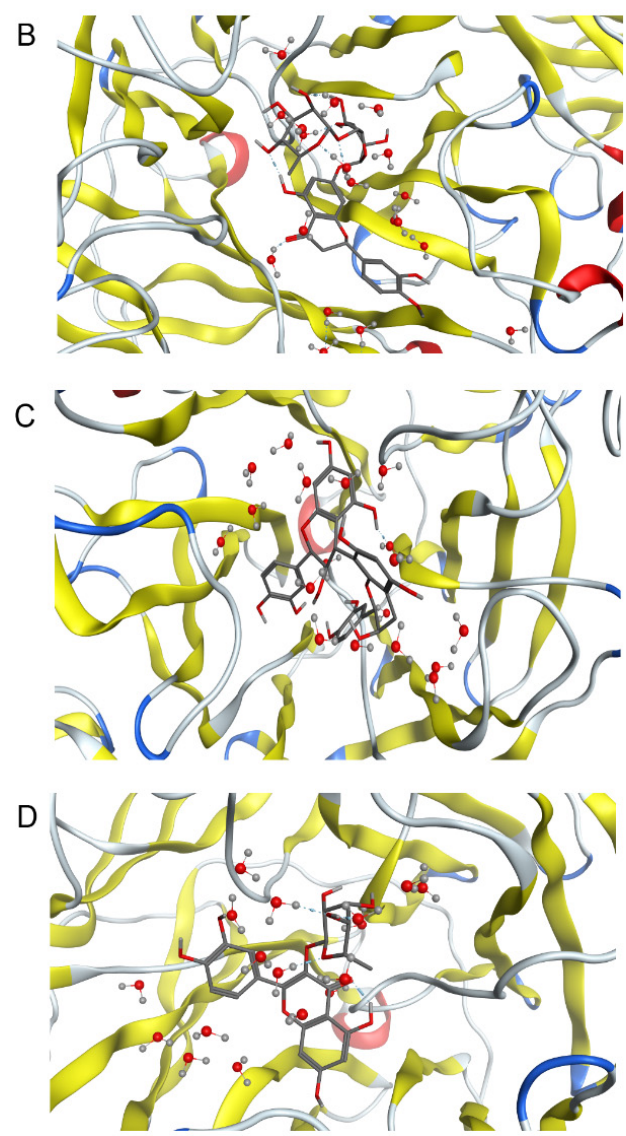

a

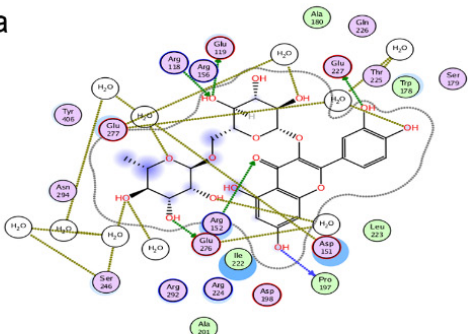

(․ㅠㅇㅛ

b
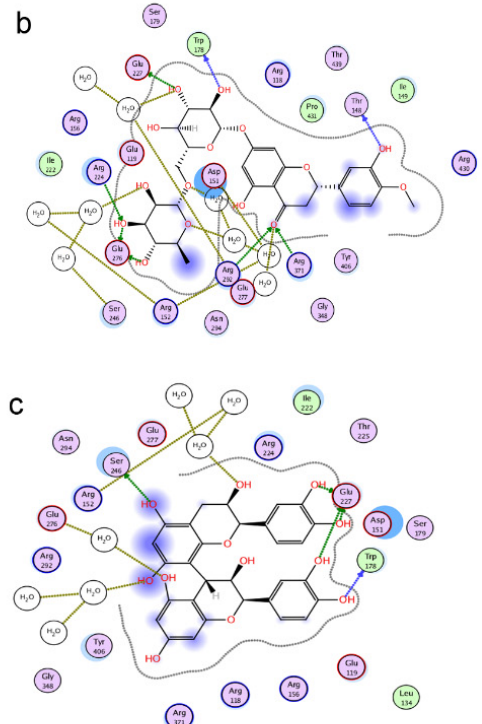

$d$

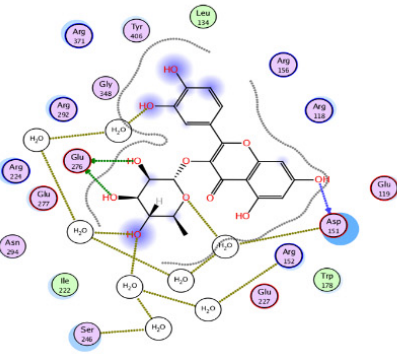

Figure 5. Predicted binding mode of four compounds with NA in three-dimensions (3D) and two-dimensions (2D) (A-D) rutin, hesperidin, procyanidin B2 and quercitrin with three-dimensional structure; (a-d) rutin, hesperidin, procyanidin B2 and quercitrin with two-dimensional structure).

\subsection{Neuraminidase (NA) Experiment of the Main Chemical Compounds}

Based on the above results of the influenza virus NA activity assay of the EA extract and eight main chemical compounds, NA experiments were conducted with the eight main chemical compounds. Oseltamivir acid was the positive control. Each component has different degrees of activity in the inhibition assay. Among them, rutin had the best effect and the order is rutin $>$ hesperidin $>$ procyanidin $\mathrm{B}_{2}>$ quercitrin $>$ eriodictyol $>$ epicatechin $>$ catechin $>$ caffeic acid, which is roughly similar to the in silico docking result. Figure 6 and Table 2 show the inhibition of NA activity and $\mathrm{IC}_{50}$ values of all the compounds. 

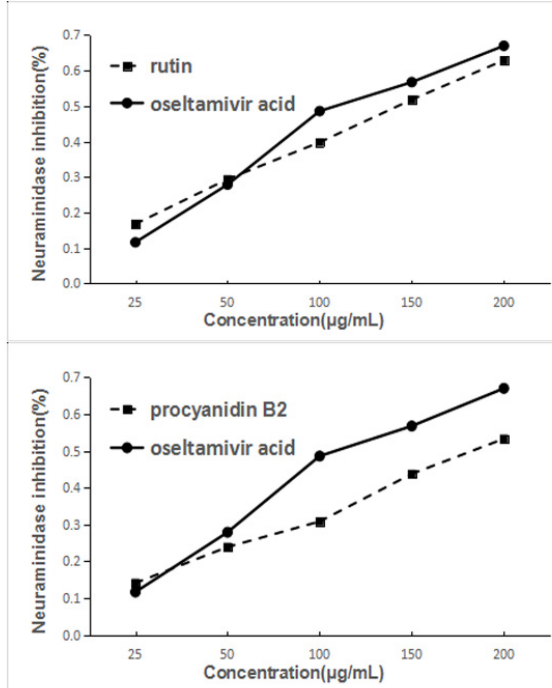

E

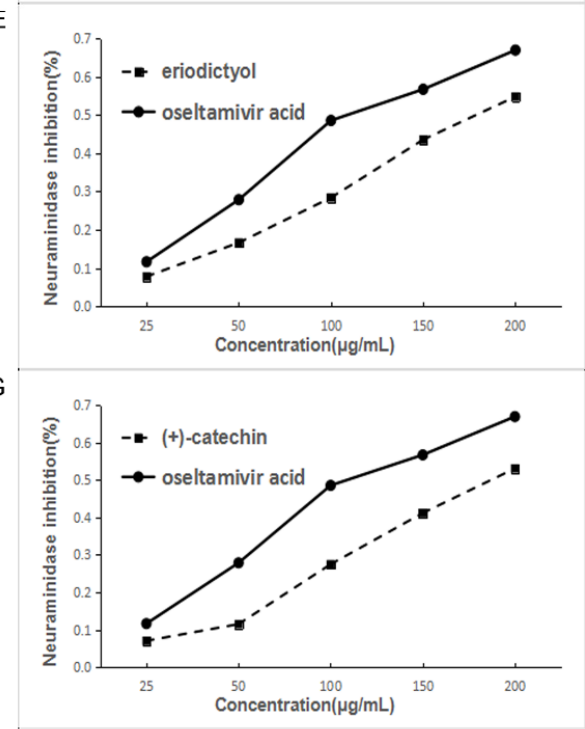

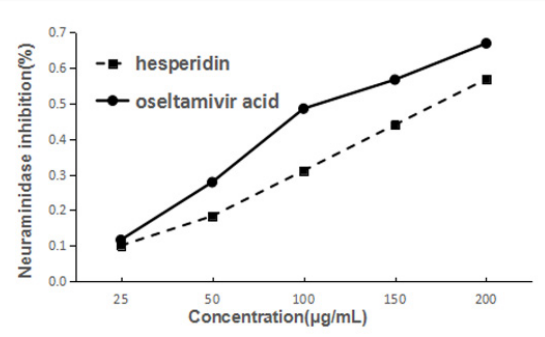

D

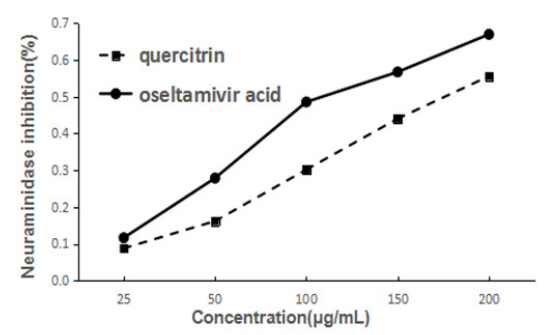

F
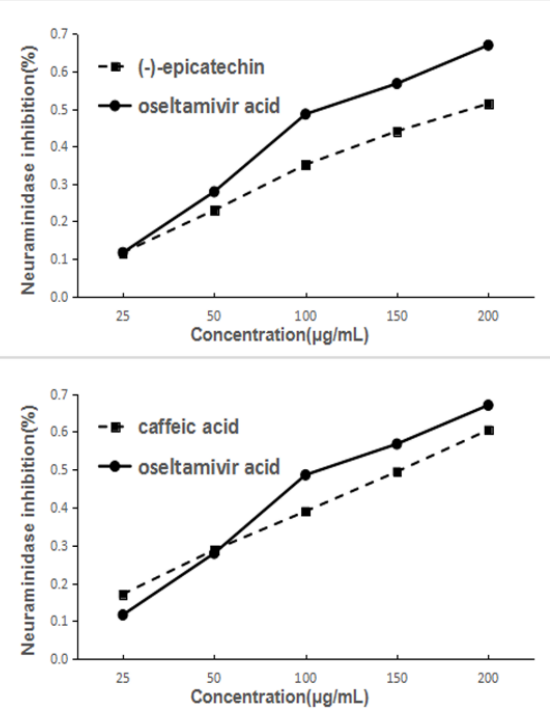

Figure 6. Inhibition of NA activity by various components of EA extract of F. dibotrys. $\left((A)\right.$, rutin; (B), hesperidin; (C), procyanidin $B_{2} ;(D)$, quercitrin; (E), eriodictyol; (F), (-)-epicatechin; (G), (+)-catechin; (H), caffeic acid).

Table 2. The $\mathrm{IC}_{50}$ values of 8 main chemical compounds in F. dibotrys on neuraminidase (NA) inhibition assay.

\begin{tabular}{ccc}
\hline Compounds & IC $_{\mathbf{5 0}}(\boldsymbol{\mu M})$ & Compound Group \\
\hline Rutin & $216.363 \pm 4.4627$ & Flavonoids \\
Hesperidin & $287.179 \pm 3.0712$ & Flavonoids \\
Procyanidin $B_{2}$ & $338.298 \pm 12.7432$ & Tannins \\
Quercitrin & $384.946 \pm 5.2333$ & Flavonoids \\
Eriodictyol & $634.116 \pm 5.18442$ & Flavonoids \\
(-)-Epicatechin & $650.370 \pm 10.6953$ & Flavonoids \\
(+)-Catechin & $660.377 \pm 6.5982$ & Flavonoids \\
Caffeic Acid & $796.218 \pm 12.4298$ & Organic acids \\
Oseltamivir Acid & $275.068 \pm 4.4973$ & \\
\hline
\end{tabular}


According to the results from the computational approach and neuraminidase (NA) experiments, the first three compounds, rutin, hesperidin, and procyanidin $B_{2}$, indeed have NA inhibitory effects. Based on this conclusion, F. dibotrys maybe have an anti-influenza virus effect.

Every year, deaths occur around the world because of the influenza virus, which has the highest morbidity among infectious diseases [22]. At present, the NA inhibitors are the first options in clinical practice against the disease. However, chemical drugs can easily cause side effects and drug-resistant virus. Thus, searching for new resources against the influenza virus is necessary and meaningful. In this paper, we demonstrated for the first time that $F$. dibotrys can cause certain NA inhibitory effects from three aspects (extracts, docking and single compounds). The present work would provide basic information and a new research direction for further further tests in vitro and clinical research on F. dibotrys.

\section{Materials and Methods}

\subsection{Plant Material and Sample Preparation}

Samples of F. dibotrys were collected in Dali, located in central Yunnan, China, in June 2012. The samples were identified by Professor Linfang Huang, and the voucher specimens (CMPB00359) were deposited in the Herbarium of the Chinese Academy of Medical Science \& Peaking Union Medicinal College. Samples of dried F. dibotrys root were crushed to a fine powder in a pulverizer. One $\mathrm{kg}$ of powder was extracted by infusion with $2.5 \mathrm{~L}$ of petroleum ether for $24 \mathrm{~h}$. Then, the residue was extracted with $80 \%$ ethanol using countercurrent extraction for three times and $2 \mathrm{~h}$ each time. The filtered extracted solutions were concentrated using a rotary evaporator to remove the ethanol solution. The concentrated solution was then successively extracted with ethyl acetate using the liquid-liquid extraction method, and the solvent was removed to obtain a dry form of the ethyl acetate fraction using a rotary evaporator. The residue was evaporated to dryness and extracted with water then evaporated to dryness, and the water extract was obtained. The four extracts were used for NA inhibition assays, and the best one was used for qualitative analysis by UPLC-Q-Exactive. The extract was dissolved in methanol at concentrations $(w / v)$ of $5 \mathrm{mg} / \mathrm{mL}$ and filtered through $0.22 \mu \mathrm{m}$ nylon micropore membranes before chemical characterization.

\subsection{Chemicals and Standard Substances}

LC-MS grade acetonitrile was purchased from Fisher Scientific (Beijing, China). De-ionized water was purified through a Milli-Q system (Millipore, Bedford, MA, USA). The analytical grade reagents used for extraction were obtained from Beijing Chemical Plant Co. Ltd. (Beijing, China). Gallic acid, ellagic acid, ethyl gallate, methyl-gallate, rutin, epicatechin, procyanidin B2, protocatechuic acid, quercitrin, hesperidin, eriodictyol, and caffeic acid were purchased from Chengdu Must Biotechnology Co. Ltd. (Chengdu, China). Oseltamivir acid was purchased from Medchem Express, LLC (Monmouth Junction, NJ, USA). Neuraminidase Inhibitors Screen Kit (NO. P0309) was purchased from Beyotime Institute of Biotechnology Co. Ltd. (Shanghai, China) and includes $10 \mathrm{~mL}$ buffer, 1 mL NA, $1 \mathrm{~mL}$ fluorescent substrate, and $1.2 \mathrm{~mL}$ Milli-Q water. Ninety six-well microplate reader (3925, Costar Company, Bethesda, MD, USA).

\subsection{Software and Docking Studies}

The protein crystal (PDB ID: 3ti3) was downloaded from the PDB database (http: / /www.rcsb.org/ $\mathrm{pdb}$ ) and docked using the Molecular Operating Environment (MOE) 2014.09 (Chemical Computing Group Inc., Montreal, QC, Canada). 


\subsection{UPLC-Q-Exactive Analysis}

\subsubsection{Liquid Chromatography}

UHPLC analysis was performed using an Ultimate 3000 system (Dionex, Sunnyvale, CA, USA), connected to an online vacuum degasser, an autosampler, a quaternary pump, and a thermostatted column compartment. The chromatographic separation column was ACQUITY UPLC HSS T3, $2.1 \mathrm{~mm} \times 100 \mathrm{~mm}, 1.7 \mu \mathrm{m}$ (Waters, Milford, MA, USA) at $40^{\circ} \mathrm{C}$. The separation conditions contain a gradient elution using acetonitrile as phase $\mathrm{A}$ and aqueous formic acid $0.1 \%(v / v)$ as mobile phase $\mathrm{B}$ at a flow rate of $0.3 \mathrm{~mL} / \mathrm{min}$. The following gradient was applied: $0-1 \mathrm{~min}, 0 \% \mathrm{~A} ; 1-10 \mathrm{~min}, 0-100 \%$ A; $10-10.1 \mathrm{~min}, 100-0 \% \mathrm{~A}$ and $10-10.1 \mathrm{~min}, 0 \% \mathrm{~A}$. The injection volume was $2 \mu \mathrm{L}$, and the injection temperature was $15^{\circ} \mathrm{C}$.

\subsubsection{Mass Spectrometry}

Mass spectrometry was executed using a Q Exactive Orbitrap MS system (Thermo Fisher, Waltham, MA, USA) with a heated electrospray ionization source for the ionization of the target compounds under the negative mode. The following are operating parameters: auxiliary gas heater temp, $300{ }^{\circ} \mathrm{C}$; spray voltage, $3.70 \mathrm{KV}$; capillary temp, $320^{\circ} \mathrm{C}$; auxiliary gas pressure, $10 \mathrm{arb}$; sheath gas pressure, 30 psi; scan modes, full MS (resolution 70,000), and scan range, 100-1500 m/z. The data were processed using the Xcalibur software (Thermo).

\subsection{Neuraminidase (NA) Inhibition Assay}

Oseltamivoir acid, four extracts and other eight compounds (all of them were tested as inhibitors) were dissolved in DMSO to give a $1 \mathrm{mg} / \mathrm{mL}$ solution. They were then diluted to $100 \mu \mathrm{g} / \mathrm{mL}$ and $200 \mu \mathrm{g} / \mathrm{mL}$ using buffer solution. The experiments were executed in a 96-well microplate reader using the procedure provided in the kit instructions. A reaction mixture containing $70 \mu \mathrm{L}$ of reaction buffer solution, $10 \mu \mathrm{L}$ of NA and $10 \mu \mathrm{L}$ of inhibitors with concentrations of $25,50,100,150$ and $200 \mu \mathrm{g} / \mathrm{mL}$ diluted from mother liquor, were added to each well respectively. Every concentration existed in three holes and they were added to $10 \mu \mathrm{L}$ Mill-Q water for each wells' buck were $90 \mu \mathrm{L}$. Vibration mixing was performed for approximately $1 \mathrm{~min}$ and incubation for $2 \mathrm{~min}$ at $37^{\circ} \mathrm{C}$, so that the NA and inhibitors react sufficiently. Afterwards, $10 \mu \mathrm{L}$ of fluorescent substrate was added to produce a total of $100 \mu \mathrm{L}$ reaction mixture. The whole mixture was completely mixed by vibration for $1 \mathrm{~min}$, and the plate was incubated for $30 \mathrm{~min}$ at $37^{\circ} \mathrm{C}$. The fluorescence was read using a microplate spectrophotometer (Molecular Devices, Gemini EM, Shanghai, China) with $322 \mathrm{~nm}$ of excitation wavelength and $450 \mathrm{~nm}$ of emission wavelength. The experiment was repeated three times. Oseltamivoir acid was used as a positive control. The inhibition (\%) was calculated using the formula:

$$
\text { NA Inhibitory activity }(\%)=\left[1-\left(\mathrm{F}_{\mathrm{s}}-\mathrm{F}_{0}\right) /\left(\mathrm{F}_{\mathrm{m}}-\mathrm{F}_{0}\right)\right] \times 100 \%
$$

$\mathrm{F}_{\mathrm{s}}$ was fluorescence intensity of inhibitors in the presence of the sample, $\mathrm{F}_{0}$ was the fluorescence intensity of the blank control and $\mathrm{F}_{\mathrm{m}}$ was the fluorescence intensity of the negative control. The $50 \%$ inhibitory concentration $\left(\mathrm{IC}_{50}\right)$ was analyzed by probit regression in SPSS (version 21, IBM SPSS, Chicago, IL, USA).

\subsection{Statistical Analysis}

NA inhibition assay was conducted in triplicate. Graph Pad Prism 6 (GraphPad, San Diego, CA, USA) and SPSS 21 were used for the statistical analysis of the data.

\section{Conclusions}

The NA inhibitory effect of F. dibotrys was revealed for the first time. An advanced UHPLC-QExactive method and a novel computational approach were developed to successfully elucidate the 
complicated chemical composition of $F$. dibotrys. A total of 32 compounds, including 13 flavonoids, one tannin, 12 organic acids, and six other compounds, were characterized. Among them, five compounds were reported for the first time in F. dibotrys. This work showed that UHPLC-Q-Exactive Orbitrap HRMS was a rapid and reliable tool for complex plant chemical component analysis and that $F$. dibotrys had NA inhibitory activity based on molecular docking. Further research is essential to explore the molecular mechanisms. Our laboratory group will further explore these effects through in anti-influenza virus experiments. This study provided scientific evidence and a new direction for future research on improving the resource efficiency of $F$. dibotrys.

Supplementary Materials: Supplementary materials are available online.

Acknowledgments: The study was supported by grants from the National Natural Science Foundation of China (81473315), Public welfare scientific research project of State Administration of traditional Chinese Medicine (201507004-2-1) and CAMS Innovation Fund for Medical Sciences(CIFMS) (no. 2016-I2M-3-015).

Author Contributions: Linfang Huang and Haibo Liu conceived and designed the experiments; Ai-Lin Liu and Jin-Hua Li performed the experiments; Yu Cao and Xiang Zhang analyzed the data; Xiang Zhang wrote the paper.

Conflicts of Interest: The authors declare no conflict of interest.

\section{References}

1. Zhu, Q.L.; Guo, T.Y.; Sui, S.Z.; Liu, G.D.; Lei, X.H.; Luo, L.L.; Li, M.Y. Molecular cloning and characterization of a novel isoflavone reductase-like gene (FCIRL) from high flavonoids-producing callus of Fagopyrum cymosum. Acta Pharm. Sin. 2009, 44, 809.

2. Liang, C.; Yuan, J.P.; Ding, T.; Yan, L.; Ling, L.; Zhou, X.F.; Zeng, Y.Q. Neuroprotective Effect of Fagopyrum dibotrys Extract against Alzheimer's Disease. Evid. Based Complement. Altern. Med. 2017, 2017, 1-9. [CrossRef] [PubMed]

3. Rui, J.; Li, H.Q.; Hu, C.L.; Jiang, Y.P.; Qin, L.P.; Zheng, C.J. Phytochemical and Pharmacological Profiles of Three Fagopyrum Buckwheats. Int. J. Mol. Sci. 2016, 17, 589. [CrossRef]

4. Wang, K.J.; Zhang, Y.J.; Yang, C.R. Antioxidant phenolic constituents from Fagopyrum dibotrys. J. Ethnopharmacol. 2005, 99, 259-264. [CrossRef] [PubMed]

5. Chen, C.; Li, A. Transcriptome Analysis of Differentially Expressed Genes Involved in Proanthocyanidin Accumulation in the Rhizomes of Fagopyrum dibotrys and an Irradiation-Induced Mutant. Front. Physiol. 2016, 7, 100. [CrossRef] [PubMed]

6. Li, C.; Feng, Z.; Bai, Y.; Chen, H.; Zhao, H.; Wu, Q. Molecular cloning and prokaryotic expression of phenylalanine ammonia-lyase gene FdPAL from Fagopyrum dibotrys. China J. Chin. Mater. Med. 2011, 36, 3238-3243.

7. Ma, J.; Wang, B.; Dai, Y.; Sui, S.Z.; Li, M.Y. Cloning and expression analysis of leucoanthocyanidin reductase gene in Fagopyrum dibotrys. Acta Pharm. Sin. 2012, 47, 953.

8. Zhang, Y.; He, P.; Zhang, C. Influences of enhanced UV-B radiation and drought stress on biomass accumulation and allocation of Fagopyrum dibotrys. Zhongguo Zhong Yao Za Zhi 2011, 36, 2032-2037. [PubMed]

9. Li, J.; Kuang, G.; Chen, X.; Zeng, R. Identification of Chemical Composition of Leaves and Flowers from Paeonia rockii by UHPLC-Q-Exactive Orbitrap HRMS. Molecules 2016, 21, 947. [CrossRef] [PubMed]

10. Lei, Q.; Liu, H.; Peng, Y.; Xiao, P. In silico target fishing and pharmacological profiling for the isoquinoline alkaloids of Macleaya cordata (Bo Luo Hui). Chin. Med. 2015, 10, 37. [CrossRef] [PubMed]

11. Yi, F.; Sun, L.; Xu, L.J.; Peng, Y.; Liu, H.B.; He, C.N.; Xiao, P.G. In silico Approach for Anti-Thrombosis Drug Discovery: P2Y1R Structure-Based TCMs Screening. Front. Pharmacol. 2016, 7, 531. [CrossRef] [PubMed]

12. Liu, J.-Q.; Dai, S.-X.; Zheng, J.-J.; Guo, Y.-C.; Li, W.-X.; Li, G.-H.; Huang, J.-F. The identification and molecular mechanism of anti-stroke traditional Chinese medicinal compounds. Sci. Rep. 2017, 7, 41406. [CrossRef] [PubMed]

13. Yi, F.; Tan, X.L.; Yan, X.; Liu, H.B. In silico profiling for secondary metabolites from Lepidium meyenii (maca) by the pharmacophore and ligand-shape-based joint approach. Chin. Med. 2016, 11, 42. [CrossRef] [PubMed]

14. Li, J.; Yang, X.; Huang, L. Anti-Influenza Virus Activity and Constituents. Characterization of Paeonia delavayi Extracts. Molecules 2016, 21, 1133. [CrossRef] [PubMed] 
15. He, C.; Peng, B.; Dan, Y.; Peng, Y.; Xiao, P. Chemical taxonomy of tree peony species from China based on root cortex metabolic fingerprinting. Phytochemistry 2014, 107, 69-79. [CrossRef] [PubMed]

16. Jiang, S.; Liu, Q.; Xie, Y.; Zeng, H.; Zhang, L.; Jiang, X.; Chen, X. Separation of five flavonoids from tartary buckwheat (Fagopyrum tataricum (L.) Gaertn) grains via off-line two dimensional high-speed counter-current chromatography. Food Chem. 2015, 186, 153-159. [CrossRef] [PubMed]

17. Kim, S.J.; Zaidul, I.S.; Suzuki, T.; Mukasa, Y.; Hashimoto, N.; Takigawa, S.; Noda, T.; Matsuura-Endo, C.; Yamauchi, H. Comparison of phenolic compositions between common and tartary buckwheat (Fagopyrum) sprouts. Food Chem. 2008, 110, 814-820. [CrossRef] [PubMed]

18. Quettier-Deleu, C.; Gressier, B.; Vasseur, J.; Dine, T.; Brunet, C.; Luyckx, M.; Cazin, M.; Cazin, J.C.; Bailleul, F.; Trotin, F. Phenolic compounds and antioxidant activities of buckwheat (Fagopyrum esculentum Moench) hulls and flour. J. Ethnopharmacol. 2000, 72, 35-42. [CrossRef]

19. Xiao, C.; Wu, M.; Chen, Y.; Zhang, Y.; Zhao, X.; Zheng, X. Revealing metabolomic variations in Cortex Moutan from different root parts using HPLC-MS method. Phytochem. Anal. 2015, 26, 86-93. [CrossRef] [PubMed]

20. Nalewajko-Sieliwoniuk, E.; Malejko, J.; Mozolewska, M.; Wolyniec, E.; Nazaruk, J. Determination of polyphenolic compounds in Cirsium palustre (L.) extracts by high performance liquid chromatography with chemiluminescence detection. Talanta 2015, 133, 38-44. [CrossRef] [PubMed]

21. Shaheen, N.; Lu, Y.; Geng, P.; Shao, Q.; Wei, Y. Isolation of four phenolic compounds from Mangifera indica L. flowers by using normal phase combined with elution extrusion two-step high speed countercurrent chromatography. J. Chromatogr. B Anal. Technol. Biomed. Life Sci. 2017, 1046, 211-217. [CrossRef] [PubMed]

22. Yang, X.Y.; Liu, A.L.; Liu, S.J.; Xu, X.W.; Huang, L.F. Screening for Neuraminidase Inhibitory Activity in Traditional Chinese Medicines Used to Treat Influenza. Molecules 2016, 21, 1138. [CrossRef] [PubMed]

Sample Availability: Samples of the compounds are not available from the authors.

(C) 2017 by the authors. Licensee MDPI, Basel, Switzerland. This article is an open access article distributed under the terms and conditions of the Creative Commons Attribution (CC BY) license (http:/ / creativecommons.org/licenses/by/4.0/). 